\title{
MECHANICAL, THERMAL, AND MORPHOLOGICAL BEHAVIOUR STUDIES ON COCONUT'SHELL AND PALM KERNEL FILLER BIOCOMPOSITE
}

\author{
Narayanan Sreeraman ${ }^{1, \star}$ \\ https://orcid.org/0000-0002-8115-3492 \\ Veeramalai Chinnasamy Sathish Gandhi ${ }^{2}$ \\ https://orcid.org/0000-0001-9977-6324 \\ Thirugnanasambandan Surendiran ${ }^{3}$ \\ https://orcid.org/0000-0003-2524-0708 \\ Radhakrishnan Kumaravelan ${ }^{4}$ \\ https://orcid.org/0000-0001-9916-7764
}

\begin{abstract}
In the present work, the composite materials were prepared from coconut shell powder, palm kernel powder, and epoxy resin. The addition of coconut shell powder was considered when preparing the composite samples, and mechanical properties such as tensile strength, hardness, impact, bending strength, physical behavior water absorption, as well as morphological tests, were conducted using Fourier Transform Infrared Spectroscopy, Scanning Electron Microscope, and Thermogravimetric Analysis for both the prepared composite material boards and chipboard. The minimal variation of tensile stress and percentage of elongation between the $50 \%$ coconut shell powder composite material and the wooden chipboard material is 4,44 MPa and $1,00 \%$, respectively, according to the findings of experimental tests. The lowest compressive stress and hardness variations between coconut shell powder composite material and wooden chipboard are found to be 0,14 MPa and 3,2 MPa, respectively. It is determined that the composite materials made from waste shell powders and epoxy resin are suitable for applications such as panel boards, automotive interior dashboards, roof sheets, and doors.
\end{abstract}

Keywords: Biocomposite material, chipboard, mechanical properties, waste shell fillers, water absorption.

\section{INTRODUCTION}

In recent years there are environmental changes drastically increased by the usage of non-degradable polymer materials and it causes environmental degradation (Laycock et al. 2017). Deforestation will affect the eco cycle due to the increase of wood-based products in engineering applications (Jiang et al. 2018). The weakness of one material is reduced by adding another one (Mariano et al. 2014). Different natural plant

\footnotetext{
${ }^{1}$ University College of Engineering Ariyalur (A Constituent College of Anna University, Chennai), Department of Mechanical Engineering, Ariyalur, Tamilnadu, India.

${ }^{2}$ University College of Engineering Nagercoil (A Constituent College of Anna University, Chennai), Department of Mechanical Engineering, Nagercoil, Kanyakumari, Tamilnadu, India.

${ }^{3}$ University College of Engineering Ariyalur (A Constituent College of Anna University, Chennai), Department of Chemistry, Ariyalur, Tamilnadu, India.

${ }^{4}$ Velalar College of Engineering and Technology, Department of Mechanical Engineering, Erode, Tamilnadu, India.

"Corresponding author: narayanansreeraman@gmail.com
}

Received: 28.02.2021 Accepted: 26.11.2021 
fillers used for composite production, such as coconut, palm kernel straw, and bamboo, can be found in the literature and industrial applications (Kai et al. 2016, Saba et al. 2014). Improve the strength of the polymer by incorporate the fillers with epoxy resin (Naghmouchi et al. 2015, Muraliraja et al. 2021). The natural materials have low mechanical properties, water resistance properties, and thermal resistance while comparing to wood filler-epoxy composite materials used in automotive, structural, etc. applications (Nagarajan et al. 2020). Availability and renewability of the waste organic filler material reduce the production cost (Arevalo-Gallegos et al. 2017). Wastages of crushed shell fillers are utilized for lightweight applications such as panel boards, automotive dashboards, etc. (Kaur et al. 2020, Dinesh et al. 2018). Lignocellulosic materials from the waste shell are now used in many applications for producing valuable products in engineering fields like chipboard and modified density fiberboard (Collins et al. 2019). The incorporation of fillers with a polymeric matrix is interested nowadays in biochemical and energy industries due to its availability and compatibility (Khalil et al. 2017, Wen et al. 2021). The economic analysis shows that the demand for waste shell fillers raises the agriculture market (H Silva et al. 2019, Rajinipriya et al. 2018). It is found that waste shell fillers price is Rupees 20 per kilogram it is justified that the low-cost composite products are manufactured (Zhang et al. 2016, Lebreton and Andrady 2019). Waste shell fillers are incorporated with thermosetting or polymer instead of wood fillers are found in various literature studies (Zaaba and Ismail 2019, Koçhan 2019, Santulli et al. 2020). The epoxy resin using agricultural waste fillers is effective in most trials. (Salasinska et al. 2018, Patil et al. 2019, Chen et al. 2020). The flexural strength and tensile strength of Date palm wood particles-based composite were decreased by increasing the filler content while the flexural modulus was increased (Kumar et al. 2018). Major advantages of using waste wood composites are easily disposed of at the end of their life cycle (Gu et al. 2017, Monteiro et al. 2017). Natural fibers have gained popularity as a suitable reinforcement in polymeric matrices in recent years due to their biodegradability, low cost, environmental friendliness, and renewable nature (Yildirim and Acay 2021, Kumar et al. 2021). This research aims to develop and characterize epoxy resin composites that are highly filled with readily available and inexpensive coconut shell and palm kernel shell ground waste material in the form of fillers, as well as investigate their mechanical behavior and percentage of filler weight, and compare them to chipboard (f) shown in Figure 1.

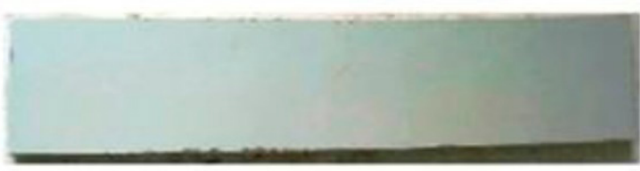

(1)

Figure 1: Chipboard.

Morphological properties of the composite materials are done through Fourier Transform Infrared Spectroscopy (FTIR), Thermogravimetric analysis (TGA) test, and Scanning Electron Microscopic (SEM) test.

\section{MATERIALS AND METHODS}

\section{Materials and fabrication}

The shells of fully matured coconuts and palm kernel were collected from Nariyal Shell Powder manufacturers in Coimbatore, India. The following procedures are done before the manufacturing of shell powders. It is first cleaned and crushed into smaller grains. These smaller grains were then subjected to repeated grinding in a pulverizing machine, after passing through cyclones and vibratory sieves fitted with phosphor-bronze mesh with average particle size $25 \mathrm{~nm}$ to $30 \mathrm{~nm}$ and density $1,0462 \mathrm{~kg} / \mathrm{m}^{3}$.

Eswar chemicals Limited, Trichy provides a low temperature curing Epoxy Water Clear Casting Resin that belongs to the 'epoxide' family of chemicals. In this test, five sample proportions are taken and blended in a 3:1 by weight ratio, as shown in Table 1 .

The epoxy filled with waste shell powder is then mechanically stirred and gradually poured into the wax-coated rectangular tray of dimension $225 \mathrm{~mm} \times 40 \mathrm{~mm} \times 10 \mathrm{~mm}$. The whole mixture is cured for $24-48$ 
hours at room temperature and prepared samples (a, b, c, d, e) are shown in Figure 2.

Table 1: Composite Sample preparation.

\begin{tabular}{|c|c|c|c|}
\hline Samples & CSP \% & PKP \% & $\begin{array}{c}\text { Epoxy Resin } \\
\text { Ratio in weight }\end{array}$ \\
\hline a & 0 & 100 & $3: 1$ \\
\hline b & 25 & 75 & $3: 1$ \\
\hline c & 50 & 50 & $3: 1$ \\
\hline d & 75 & 25 & $3: 1$ \\
\hline e & 100 & 0 & $3: 1$ \\
\hline
\end{tabular}

CSP: Coconut shell powder PKP: Palm kernel powder.
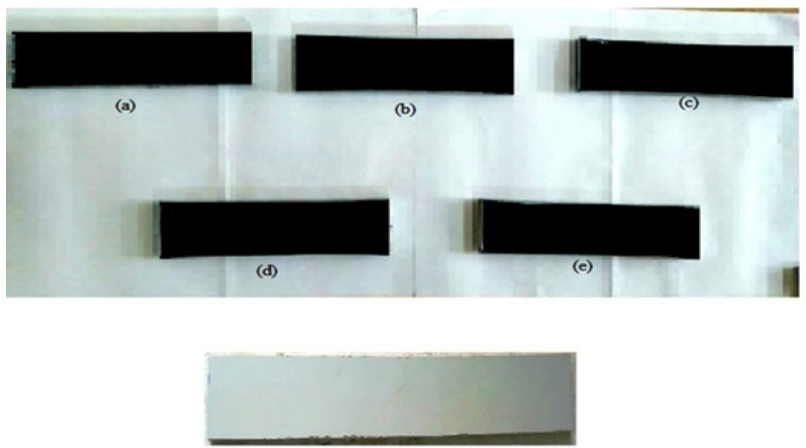

(1)

Figure 2: CSP Composite samples.

\section{Testing of samples}

The various mechanical properties such as tensile strength, hardness, impact strength, bending strength, and water absorption tests are conducted for prepared materials according to the American Society for Testing and Materials (ASTM 2021) international standard data.

\section{Tensile test}

The tensile test was carried out using the universal testing machine with a gripping capacity of $100 \mathrm{kN}$. The testing was performed at an ambient temperature of $24{ }^{\circ} \mathrm{C}$ and relative humidity of $53 \%$. The specimen was mounted by its ends into the holding grips of the universal testing machine. The machine is designed to elongate the specimen at a uniform rate and using an extensometer the instantaneous applied load and the resulting elongation of break are measured continuously until the break and results are shown in Table 2 .

Table 2: Tensile stress and percentage of elongation of the materials.

\begin{tabular}{|c|c|c|}
\hline Materials & Tensile stress (MPa) & Elongation (\%) \\
\hline Chipboard & 23,62 & 1,78 \\
\hline $0 \%$ CSP & 15,94 & 1,36 \\
\hline $25 \%$ CSP & 23,1 & 1,59 \\
\hline $50 \%$ CSP & 23,56 & 1,67 \\
\hline $75 \%$ CSP & 15,82 & 1,46 \\
\hline $100 \%$ CSP & 17,49 & 1,52 \\
\hline
\end{tabular}




\section{Bend Test}

The three-point bend tests of composite specimens are carried out using a universal testing machine and results are shown in Table 3.

Table 3: The compressive stress of the materials.

\begin{tabular}{|c|c|}
\hline Materials & Compressive stress (MPa) \\
\hline Chipboard & 16,58 \\
\hline $0 \%$ CSP & 13,68 \\
\hline $25 \%$ CSP & 15,97 \\
\hline $50 \%$ CSP & 16,72 \\
\hline $75 \%$ CSP & 14,68 \\
\hline $100 \%$ CSP & 15,20 \\
\hline
\end{tabular}

\section{Impact test}

\section{Izod impact test}

Impact Tester used for both Izod and Charpy test is common. The apparatus contains a pendulum with a known dead-weight at the end of its arm swinging down and hitting the specimen while it is held tightly in a vertical position. The impact strength is found by the loss of energy of the pendulum. The prepared specimen has dimensions of $64 \mathrm{~mm} \times 13 \mathrm{~mm} \times 10 \mathrm{~mm}$ and $2 \mathrm{~mm} \mathrm{~V}$-notch at an angle of $45^{\circ}$ facing towards the pendulum with a striking distance of $32 \mathrm{~mm}$ from the upper tip of the specimen.

\section{Charpy impact test}

The apparatus contains a pendulum with a known dead-weight at the end of its arm swinging down and hitting the specimen while it is held tightly in a horizontal position. The impact strength is found by the loss of energy of the pendulum. The prepared specimen has dimensions of $55 \mathrm{~mm} \times 10 \mathrm{~mm} \times 10 \mathrm{~mm}$ and $2 \mathrm{~mm}$ $\mathrm{V}$ - notch at an angle of $45^{\circ}$ facing away from the pendulum with a striking point at the middle of the specimen. The material impact strength results from the Izod and Charpy tests are shown in Table 4.

Table 4: Impact on materials.

\begin{tabular}{|c|c|c|}
\hline \multirow{2}{*}{ Materials } & \multicolumn{2}{|c|}{ Impact strength (MPa) } \\
\cline { 2 - 3 } & Izod & Charpy \\
\hline Chipboard & 4,2 & 3,2 \\
\hline $0 \%$ CSP & 3,8 & 2,8 \\
\hline $25 \%$ CSP & 4,0 & 2,8 \\
\hline $50 \%$ CSP & 4,2 & 3,4 \\
\hline $75 \%$ CSP & 3,8 & 3,2 \\
\hline $100 \%$ CSP & 4,0 & 3,2 \\
\hline
\end{tabular}

\section{Microhardness measurement}

The hardness of the prepared materials was studied by Vickers's microhardness test. The hardness of the material is defined as the resistance offered by it to the motion of dislocations, deformations, or damage under applied stress. To measure the hardness, prepared materials with a thickness of $10 \mathrm{~mm}$ were used and loads of different magnitudes were applied.

In these equations, which have the dimensions of stress, load $\mathrm{F}$ and diagonal length $\mathrm{D}$ are measured respectively. The variation of hardness with different loads for materials is shown in Table 5. Vickers hardness number (HV) was calculated for the materials by using the Equation 1. 
HV- Vickers number in HV

$$
\mathrm{HV}=1,85\left(\frac{\mathrm{F}}{\mathrm{D}^{2}}\right)
$$

F - Applied load in N

$\mathrm{D}^{2}$ - Area of the indentation in $\mathrm{m}^{2}$

Table 5: Vickers Microhardness of the materials.

\begin{tabular}{|c|c|c|c|c|c|}
\hline \multirow{2}{*}{ Materials } & \multicolumn{5}{|c|}{ Vickers Microhardness (HV) at different loads in grams } \\
\cline { 2 - 6 } & 25 & 50 & 100 & 200 & 500 \\
\hline Chipboard & 15,12 & 23,46 & 39,31 & 39,30 & 71,40 \\
\hline $0 \%$ CSP & 11,05 & 12,25 & 20,70 & 35,30 & 56,15 \\
\hline $25 \%$ CSP & 13,50 & 21,65 & 32,60 & 40,35 & 75,55 \\
\hline $50 \%$ CSP & 18,55 & 25,85 & 39,30 & 51,30 & 75,60 \\
\hline $75 \%$ CSP & 13,20 & 16,85 & 18,00 & 24,10 & 51,15 \\
\hline $100 \%$ CSP & 16,15 & 19,25 & 35,65 & 50,45 & 71,60 \\
\hline
\end{tabular}

\section{Water absorption test}

A water absorption test was carried out for the five specimen materials of each $4 \mathrm{~g}$ weight is weighed with a precision of $0,001 \mathrm{~g}$ weighing machine and the sample materials were dried in an oven for 24 hours at $80{ }^{\circ} \mathrm{C}$. The sample materials are immersed in both distilled water and sodium chlorinated water for 24 hours for 5 days at room temperature $24^{\circ} \mathrm{C}$.

At the end of the immersed periods, the specimens were removed from both the distilled water and salt water wet specimens weight values were determined. The water absorption was calculated from Equation 2 and the results are shown in Table 6.

$$
\text { Water absorption }(\%)=\frac{m_{0}-m_{1}}{m_{1}} \times 100
$$

Where

$\mathrm{m}_{0}$ - Initial mass of specimen material $(\mathrm{g})$

$\mathrm{m}_{1}$ - Mass of specimen material after drying $(\mathrm{g})$ 
Table 6: Water absorption of tested materials.

\begin{tabular}{|c|c|c|c|c|c|c|c|c|c|c|}
\hline \multirow{3}{*}{ Materials } & \multicolumn{9}{|c|}{ Water absorption (\%) } \\
\cline { 2 - 13 } & \multicolumn{9}{|c|}{ Distilled water } & \multicolumn{5}{c|}{ Saltwater } \\
\cline { 2 - 12 } & Day 1 & Day 2 & Day 3 & Day 4 & Day 5 & Day 1 & Day 2 & Day 3 & Day 4 & Day 5 \\
\hline Chipboard & 8,54 & 19,9 & 35,9 & 48,12 & 63,42 & 5,81 & 14,68 & 28,3 & 36,34 & 43,85 \\
\hline $0 \%$ CSP & 0 & 0 & 0 & 0 & 0 & 0 & 0 & 0 & 0 & 0 \\
\hline $25 \%$ CSP & 0 & 0 & 0 & 0 & 0 & 0 & 0 & 0 & 0 & 0 \\
\hline $50 \%$ CSP & 0 & 0 & 0 & 0 & 0 & 0 & 0 & 0 & 0 & 0 \\
\hline $75 \%$ CSP & 0 & 0 & 0 & 0 & 0 & 0 & 0 & 0 & 0 & 0 \\
\hline $100 \%$ CSP & 0 & 0 & 0 & 0 & 0 & 0 & 0 & 0 & 0 & 0 \\
\hline
\end{tabular}

\section{Time duration for drilling}

The materials having dimensions of $210 \mathrm{~mm} \times 40 \mathrm{~mm} \times 10 \mathrm{~mm}$ are placed separately in a vice and clamped firmly, the HSS drill of $8 \mathrm{~mm}$ diameter is placed perpendicular to the material where the hole to be made and the time of a drill to make a through-hole is noted with a stopwatch is shown in Table 7.

Table 7: Duration period for drilling.

\begin{tabular}{|c|c|}
\hline Materials & Time (s) \\
\hline Chipboard & 10,84 \\
\hline $0 \%$ CSP & 11,18 \\
\hline $25 \%$ CSP & 11,17 \\
\hline $50 \%$ CSP & 11,24 \\
\hline $75 \%$ CSP & 11,18 \\
\hline $100 \%$ CSP & 11,06 \\
\hline
\end{tabular}

\section{Morphological studies}

\section{Scanning electron microscope (SEM)}

The morphological studies of the samples were carried out by using a scanning electron microscope (SEM). SEM micrographs of the surfaces of the Materials were taken by using a ZEISS Evo ${ }^{\circledR}$ LS10 scanning electron microscope. The samples were first sputter-coated with a fine layer of gold under vacuum for $60 \mathrm{~s}$. An accelerating voltage of $20 \mathrm{kV}$ was used to get the SEM images.

\section{Fourier transform infrared spectroscopy (FTIR) analysis}

For finding the different functional groups in the materials were studied by FTIR in the ACIC Instrumentation center in St. Joseph's College, Tiruchirappalli. The FTIR spectra were recorded employing a Perkin Elmer make and Model Spectrum - II which was equipped with a germanium ATR crystal probe and allows direct recording of the spectra without sample preparation. The recorded spectra were averages of 32 scans over the often range $4000 \mathrm{~cm}^{-1}$ to $400 \mathrm{~cm}^{-1}$ at $4 \mathrm{~cm}^{-1}$ resolutions. 


\section{Thermogravimetric analysis (TGA)}

Thermal stability of the materials was determined by Thermogravimetric analysis realized in the temperature range of $30{ }^{\circ} \mathrm{C}$ to $900{ }^{\circ} \mathrm{C}$ at a heating rate of $10 \mathrm{~J} / \mathrm{s}$ under nitrogen atmosphere, using a TG $209 \mathrm{~F} 1 \mathrm{Libra}$ apparatus (Erich NETZSCH GmbH \& Co. Holding KG, Selb, Germany). $5 \mathrm{mg} \pm 0,1 \mathrm{mg}$ samples were placed on ceramic pans.

\section{RESULTS AND DISCUSSION}

The various mechanical properties such as tensile strength, hardness, impact strength, compressive stress, and physical behavior like percentage of water absorption and also the characterization study have been conducted for both the prepared composite material and chipboard with the help of FTIR, SEM, and TGA. The physical behavior study has been carried out in the CPS composite materials and wooden chipboard by soaked the samples in normal water and sodium chlorinated water for 5 days.

The increase of CSP filler from $0 \%$ to $50 \%$ the tensile stress and percentage of elongation of material has been increased and its maximum value of $23,56 \mathrm{MPa}$ and $1,67 \%$ for $50 \% \mathrm{CSP}$ composite material. And further increasing of CSP filler from $75 \%$ to $100 \%$ both the tensile and percentage of elongation is decreased due to the poor bonding of CSP and PKP filler materials (Shahzad 2015). The tensile stress and elongation of a percentage of chipboard material are $23,62 \mathrm{MPa}$ and 1,78 \% respectively. The results of both CSP composite materials and chipboard material are compared and shown in Figure 3. It shows that the deviation of tensile stress and percentage of elongation for $50 \%$ CSP composite material and chipboard is $0,06 \mathrm{MPa}$ and $0,11 \%$ respectively. These variations are quite small as compared with the rest of the CSP composite materials and chipboard.

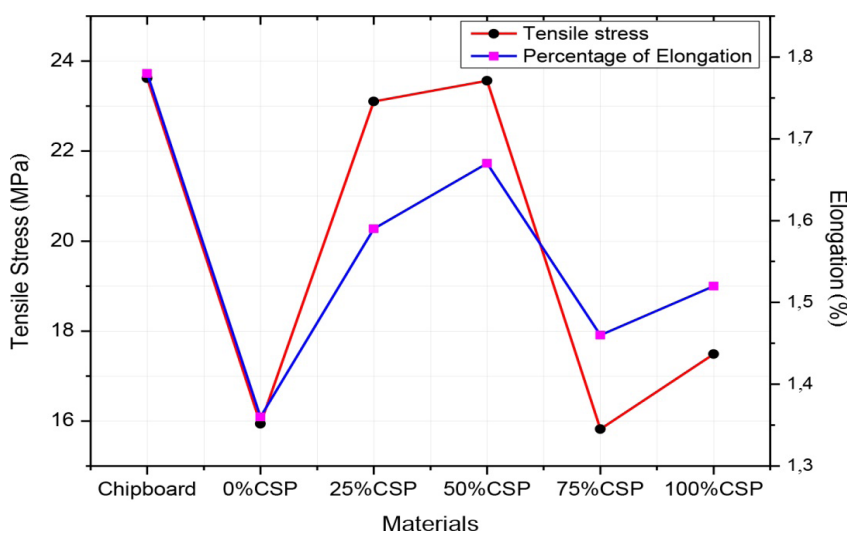

Figure 3: Tensile stress and Percentage of elongation of the materials.

With the increase of CSP filler from $0 \%$ to $50 \%$ it is observed that the compressive stress is increased and its maximum value of $16,72 \mathrm{MPa}$ for $50 \% \mathrm{CSP}$ composite material. And further increasing the percentage from $75 \%$ to $100 \%$ it is identified that the crack formation has been occurred at 15 MPa due to the low bonding strength with increased PKP filler materials.

The percentage variation of compression stress value between $50 \%$ CSP Material and the chipboard is $0,14 \%$ and the results are shown in Figure 4. The compression stress variation is low down as compared with the rest of the CSP composite materials and chipboard. 


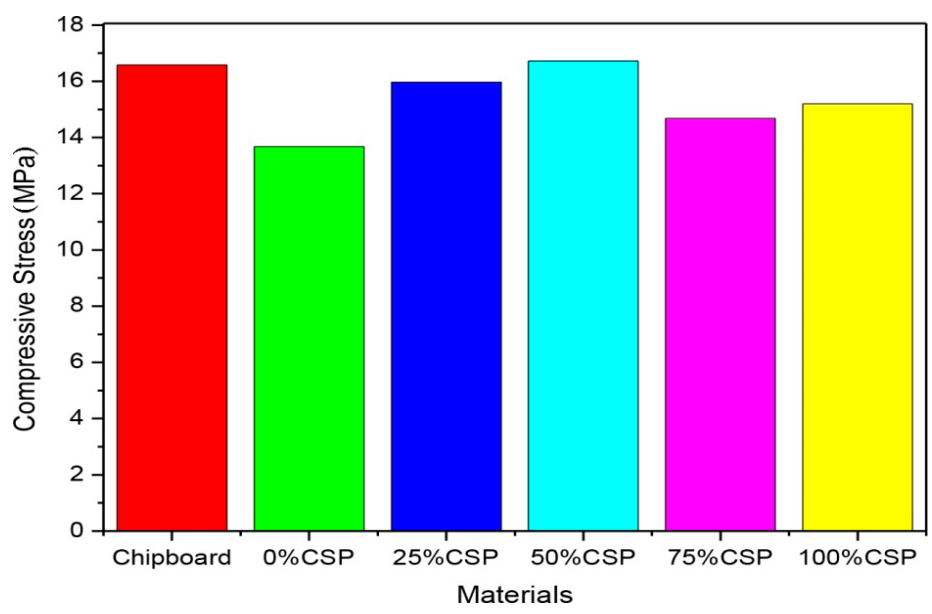

Figure 4: The compressive stress of the materials.

Figure 5 shows the impact values of CSP composite materials and chipboard. The impact tests of the CSP composite materials and wooden chipboard material are carried out in the Izod and Charpy tests. It is observed that the $50 \%$ CSP composite material has taken up the maximum impact strength as compared with the rest of the percentage of CSP composite materials. It is identified that in the Izod impact test both $50 \%$ CSP composite material and chipboard are take-up the same impact load. In the Charpy impact test, the minimum impact is 0,2 Mpa between $50 \%$ CSP composite material and chipboard.

The different load values of $25 \mathrm{~g}, 50 \mathrm{~g}, 100 \mathrm{~g}, 200 \mathrm{~g}$, and $500 \mathrm{~g}$ are applied to estimate the hardness in CSP composite material and chipboard. While applying the load of $25 \mathrm{~g}, 50 \mathrm{~g}, 100 \mathrm{~g}, 200 \mathrm{~g}$, and $500 \mathrm{~g}$ the hardness values are increased in the $0 \%$ to $50 \%$ CSP composite materials and it's further decreasing in the $75 \%$ and $100 \%$ CSP composite materials.

It is observed that the $50 \%$ CSP composite material having a high average hardness value than the chipboard shown in Figure 6.

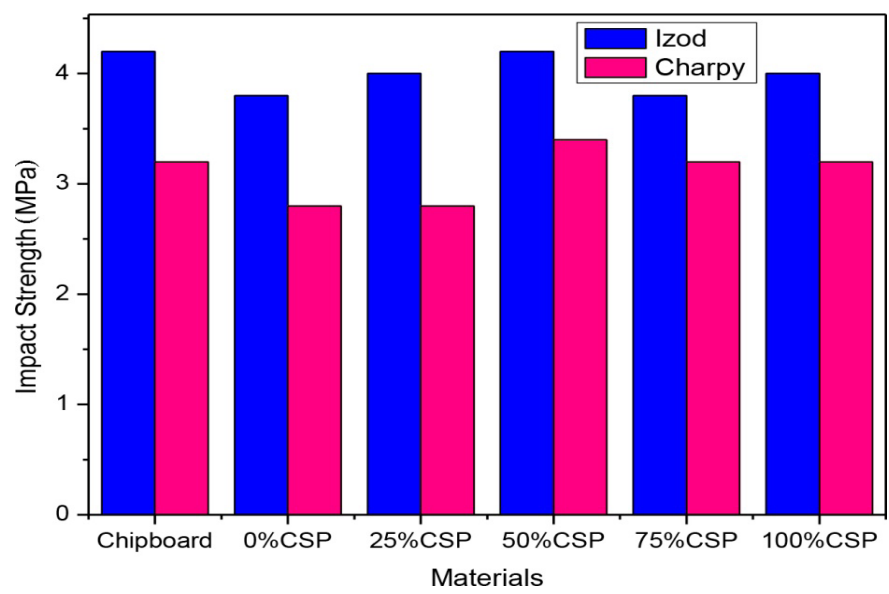

Figure 5: Impact of the materials. 


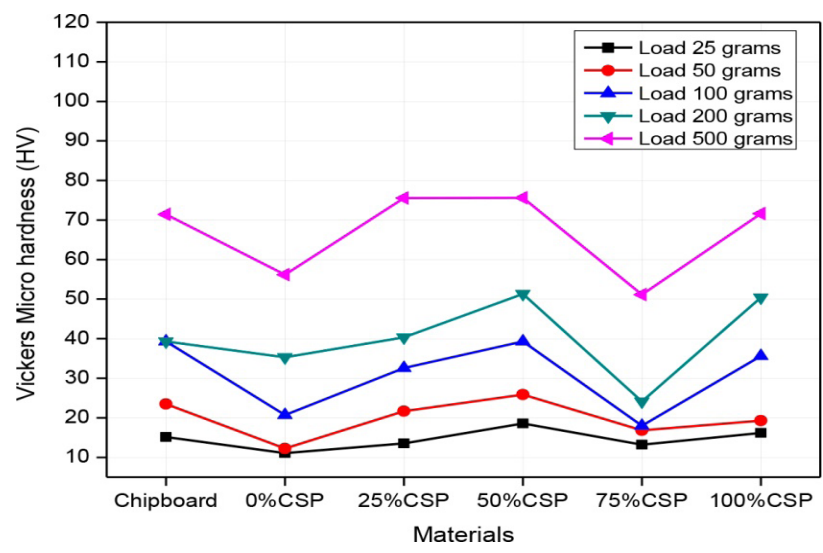

Figure 6: Hardness of the materials.

The percentage of distilled and saltwater absorption of the CSP composite materials that have been observed for 5 days is shown in Figures $7 \mathrm{a}$ and Figure $7 \mathrm{~b}$ respectively. From the results, it is identified that the distilled and saltwater absorption percentages are zero (No water absorption) for the CSP composite materials, and for the chipboard, the distilled water absorption rate is increased between $8,54 \%$ and $63,42 \%$ and in the saltwater, the percentage of water absorption is increased between $5,81 \%$ and $43,85 \%$ is due to the layer of salt formation in the surface.
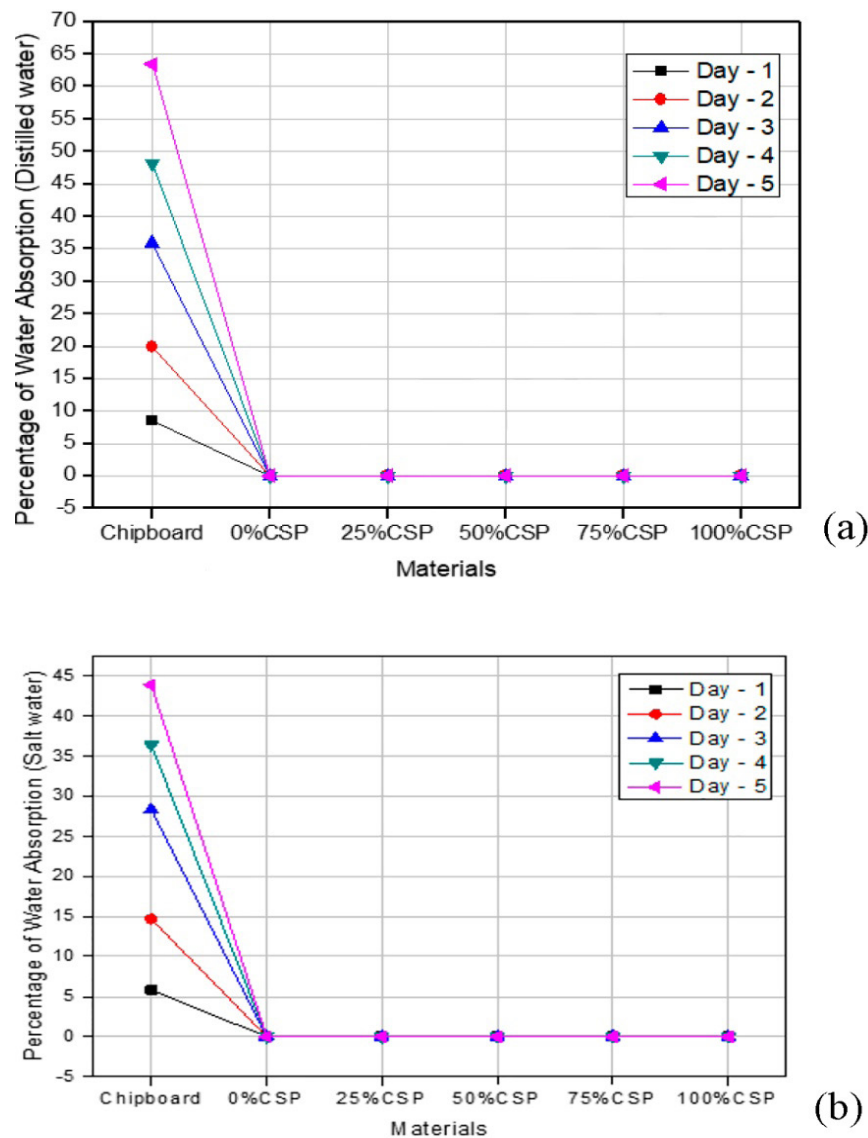

(b)

Figure 7: (a) Percentage of normal and (b) saltwater absorbed by the materials. 
Figure 8 shows that the time taken for a drill is 10,84 seconds which is the minimum for chipboard as compared with CSP composite materials. But the interior surface of the drilled hole is smooth and even surfaces are formed in the CSP composite materials.

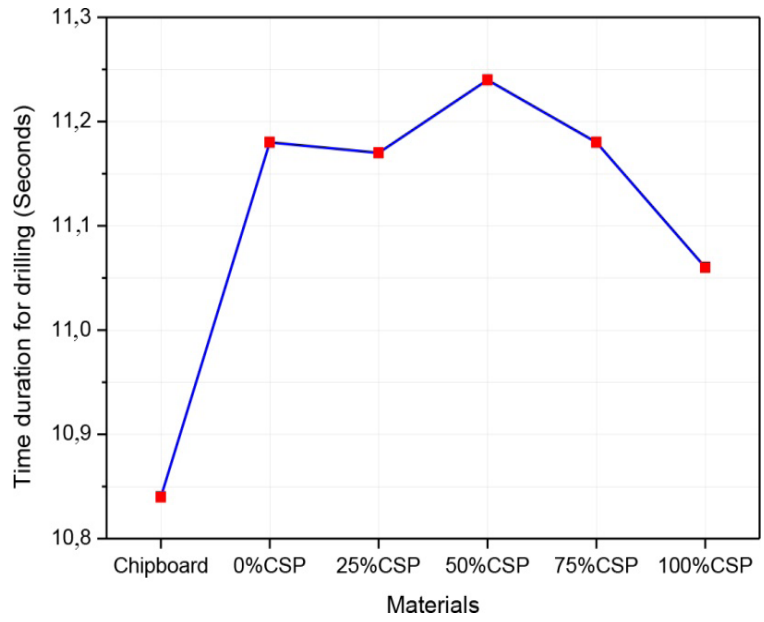

Figure 8: Time of drilling.

In chipboard (f), the drilled surface is not uniform due to low bonding strength. This causes damage to the material and the chips are stick out in the inner surface of the drilled portion as shown in Figure 9.
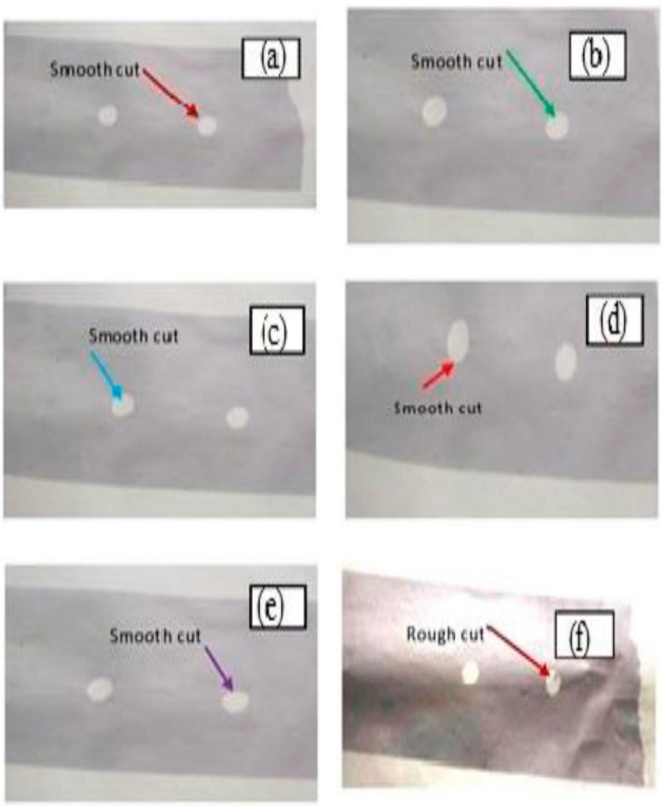

Figure 9: Drilled holes on composite materials.

Fourier-transform infrared spectroscopy (FTIR) analysis is carried out for both the CSP composite materials and the chipboard are carried out and the results are shown in Figure.10. The broad absorption band at $3500 \mathrm{~cm}^{-1}$ indicates bonded hydroxyl -OH groups existing in the organic filler. Absorption peaks at wave numbers of around $2887 \mathrm{~cm}^{-1}, 1744 \mathrm{~cm}^{-1}$, and $1054 \mathrm{~cm}^{-1}$ are assigned to $-\mathrm{CH}, \mathrm{C}=\mathrm{O}$, and $\mathrm{C}-\mathrm{O}$ stretching's, respectively Moreover, the observed peak at $1623 \mathrm{~cm}^{-1}$ corresponds to $\mathrm{C}=\mathrm{C}$ stretching and confirms the presence of lignin and its aromatic group in the natural filler. At epoxy resin and composite sample spectra, the vibration band at $936 \mathrm{~cm}^{-1}$, resulting from C-O deformation of the oxirane group, was recorded. The sample containing $50 \%$ of CSP composite materials shown a strong decrease in absorbance at this intensity therefore, 
it can be stated that the curing process was modified by the presence of the organic filler.
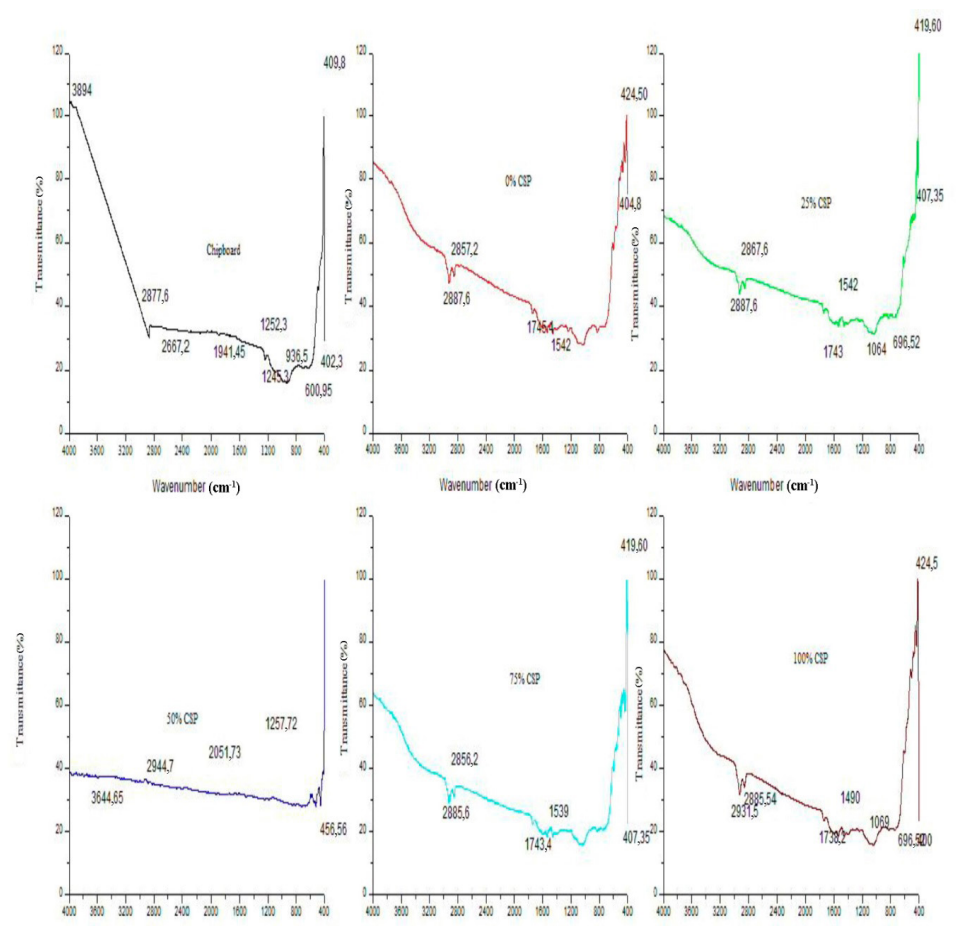

Warenumber $\left(\mathbf{c m}^{1}\right)$

Warenumber (cmi')

Warenumber (cm')

Figure 10: FTIR analysis of the materials.

In the Scanning electron microscope analysis, the images are taken at $500 \mathrm{X}$ magnification are shown in Figure 11a, Figure 11b, Figure 11c, Figure 11d, Figure 11e and Figure 11f. It is observed that there is a uniform mixing of fillers and Epoxy in $50 \%$ and $100 \%$ CSP composite materials shown in Figure 11c and Figure 11e.

For the $25 \%$ and $75 \%$ CSP composite materials the filler particles are scattered and dispersed than $0 \%$ CSP composite materials as shown in Figures 11b, Figure 11d, and Figure 11a and for the chipboard, there are small voids that are presented between the materials is shown in Figure 11f.
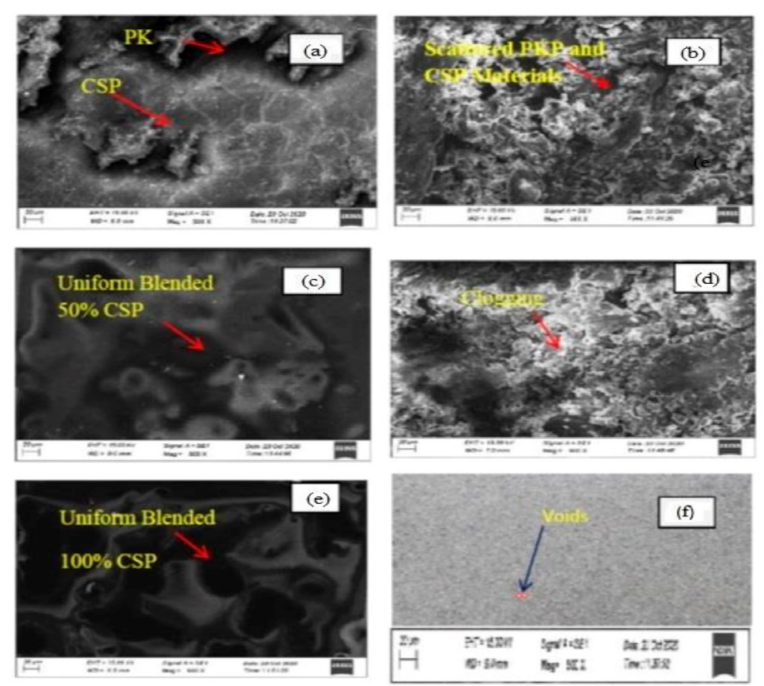

Figure 11: SEM images of composite materials. 
The thermal stability of the materials is evaluated by Thermo-gravimetric analysis. The results are shown in Figure 12. It is noted that the CSP composite materials built-in with epoxy resin showed better stability and it is having a mass percentage more than the chipboard. The mass of the materials has been loosed between the temperatures $180^{\circ} \mathrm{C}$ to $215^{\circ} \mathrm{C}$ further it is constant between $215^{\circ} \mathrm{C}$ and $900{ }^{\circ} \mathrm{C}$.

It shows that the lowest improvement in thermal stability, measured the temperature for $5 \%$ mass loss at $17{ }^{\circ} \mathrm{C}$, while the highest at $35{ }^{\circ} \mathrm{C}$ for samples containing $15 \%$ and $25 \%$ of the filler respectively. At $50 \%$ mass loss, may be observed.

The maximum temperature for epoxy resin was found. It is measured at $350{ }^{\circ} \mathrm{C}$, the material residual increased with increasing the number of organic fillers.

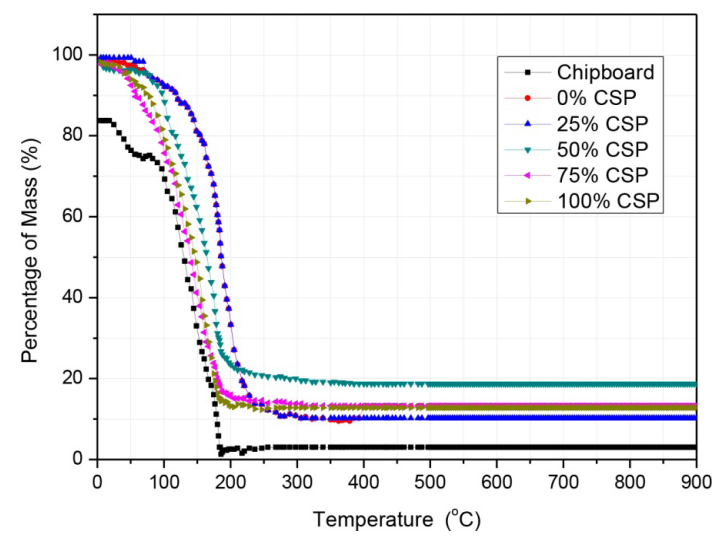

Figure 12: TG curve of materials.

\section{CONCLUSIONS}

The experimental studies are carried out on the coconut shell powder (CSP) is added with both palm kernel powder (PKP) with the epoxy resin (i.e., CSP composite materials) and chipboard. The various mechanical properties such as tensile strength, compressive strength, impact strength, and hardness are determined. The water absorption test, time taken for drilling, FTIR analysis, SEM analysis, and TGA analysis are carried out. The following are conclusions arrived at from the present studies.

It is observed that the $50 \%$ CSP composite material is greatly influenced by the PKP filled volume fraction and it is good.

The water absorption tests are carried out in both the normal water and saltwater mediums, it is observed that the water absorption is zero percent in the CSP composite materials but in the chipboard, it is gradually increased in both the mediums.

It is identified that the time taken for drilling a hole in $50 \%$ CSP composite material has taken more time than the other materials, but the drilled inner surfaces are smooth and even in CSP composite materials than a clipboard.

The FTIR analysis is carried out and found the chemical and its groups for all the materials.

SEM analysis shows that in the $50 \%$ and $100 \%$ CSP composite materials the fillers are uniformly mixed than the other materials.

From TGA results it is found that the maximum temperature was found for epoxy resin while increasing of Waste Shell powder caused a gradual decrease of $50 \%$ mass loss temperature.

The composite prepared with $50 \%$ CSP composite material having good tensile strength, less weight density, and good water resistance. It is suitable for various applications such as panel boards, an interior dashboard in automobiles, roof sheets, and doors.

Because of this, for more decades, the problem of plastic waste littering the earth and collecting in the 
oceans will remain a problem in creating biodegradable polymers/blends/composites that can replace all other non-biodegradable polymers, governments have been able to give more attention and increase the usage of biocomposites in various applications.

\section{ACKNOWLEDGMENTS}

We gratefully acknowledged University College of Engineering Nagercoil and the University College of Engineering Ariyalur provided laboratory facilities for the present work carried out.

\section{REFERENCES}

Arevalo-Gallegos, A.; Ahmad, Z.; Asgher, M.; Parra-Saldivar, R.; Iqbal, H.M.N. 2017. Lignocellulose: a sustainable material to produce value-added products with a zero-waste approach-a review. Int J Biol Macromol 99: 308-318. https://doi.org/10.1016/j.ijbiomac.2017.02.097

ASTM. 2021. Composite test methods according to American Society for Testing and Materials Standards International Worldwide. https://www.partneresi.com/resources/glossary/american-society-testing-and-materials-astm

Chen, C.; Kuang, Y.; Zhu, S.; Burgert, I.; Keplinger, T.; Gong, A.; Li, T.; Berglund, L.; Eichhorn, S.J.; Hu, L. 2020. Structure-property-function relationships of natural and engineered wood. Nat Rev Mater 5(9): 642-666. https://doi.org/10.1038/s41578-020-0195-z

Collins, M.N.; Nechifor, M.; Tanasă, F.; Zănoagă, M.; McLoughlin, A.; Stróżyk, M.A.; Culebras, M.; Teacă, C.A. 2019. Valorization of lignin in polymer and composite systems for advanced engineering applications-a review. Int J Biol Macromol 131: 828-849. https://doi.org/10.1016/j.ijbiomac.2019.03.069

Dinesh, S.; Elanchezhian, C.; Vijayaramnath, B.; Ramadhass, R. 2018. Experimental Investigation Of Composite Materials. Int J Eng Math 7(4): 508-544. http://www.ijesm.co.in

Gu, F.; Guo, J.; Zhang, W.; Summers, P.A.; Hall, P. 2017. From waste plastics to industrial raw materials: A life cycle assessment of mechanical plastic recycling practice based on a real-world case study. Sci Total Environ 601:1192-1207. https://doi.org/10.1016/j.scitotenv.2017.05.278

Silva, T.H.; Mesquita-Guimarães, J.; Henriques, B.; Silva, F.S.; Fredel, M.C. 2019. The potential use of oyster shell waste in new value-added by-products. Resources (1): 13. https://doi.org/10.3390/resources 8010013

Jiang, F.; Li, T.; Li, Y.; Zhang, Y.; Gong, A.; Dai, J.; Hitz, E.; Luo, W.; Hu, L. 2018. Wood-based nanotechnologies toward sustainability. Adv Mater 30(1): 1703453. https://doi.org/10.1002/adma.201703453

Kai, D.;Tan, M.J.; Chee, P.L.; Chua, Y.K.; Yap, Y.L.; Loh, X.J. 2016. Towards lignin-based functional materials in a sustainable world. Green Chem 18(5): 1175-1200. https://doi.org/10.1039/c5gc02616d

Kaur, M.; Mehta, A.; Bhardwaj, K.K.; Gupta, R. 2020. Bionanomaterials from Agricultural Wastes. Vol. 126, in Green Nanomaterials. Advanced Structured Materials, edited by Ali, W; Ahmed, S. 243-260. Springer. https://doi.org/10.1007/978-981-15-3560-4_10

Khalil, H.P.S.; Tye, Y.Y.; Saurabh, C.K.; Leh, C.P.; Lai, T.K.; Chong, E.W.N.; Fazita, M.R.; Hafiidz, J.M.; Banerjee, A.; Syakir, M.I. 2017. Biodegradable polymer films from seaweed polysaccharides: A review on cellulose as a reinforcement material. eXPRESS Polym Lett 11(4): 244-265. https://doi.org/10.3144/ expresspolymlett.2017.26

Koçhan, C. 2019. Mechanical properties of waste mussel shell particles reinforced epoxy composites. Mater Test 61(2): 149-154. https://doi.org/10.3139/120.111298

Kumar, A.; Krithiga, T.; Venkatesan, D.; Joshua Amarnath, D. 2021. Green Composites. Materials Horizons Composites. Materials Horizons: From Nature to Nanomaterials, edited by Balakrishnan, P; Thomas, S. Singapore: Springer. https://doi.org/10.1007/978-981-15-9643-8_9

Kumar, R.; Kumar, K.; Bhowmik, S. 2018. Mechanical characterization and quantification of tensile, fracture, and viscoelastic characteristics of wood filler reinforced epoxy composite. Wood Sci Technol 52(3): 677-699. https://doi.org/10.1007/s00226-018-0995-0 
Laycock, B.; Nikolić, M.; Colwell, J.M.; Gauthier, E.; Halley, P.; Bottle, S.; George, G. 2017. Lifetime prediction of biodegradable polymers. Prog Polym Sci 71: 144-189. https://doi.org/10.1016/j.progpolymsci.2017.02.004

Lebreton, L.; Andrady, A. 2019. Future scenarios of global plastic waste generation and disposal. Palgrave Commun 5(1): 1-11. https://doi.org/10.1057/s41599-018-0212-7

Mariano, M.; El Kissi, N.; Dufresne, A. 2014. Cellulose nanocrystals and related nanocomposites: Review of some properties and challenges. J Polym Sci B Polym Phys 52 (12): 791-806. https://doi.org/10.1002/ polb.23490

Monteiro, P.J.; Miller, S.A.; Horvath, A. 2017. Towards sustainable concrete. Nat Mater 16 (7): 698699. https://doi.org/10.1038/nmat4930

Muraliraja, R.; Tamilarasan, T.R.; Udayakumar, S.; Pandian, C.A. 2021. The Effect of Fillers on the Tribological Properties of Composites. In Composites Science and Technology, edited by Mohd Jamir, M.R.; Abdul Majid, M.S.; Azmi, A.I.; Saba, N.; Hameed Sultan, M.T. 243-266. Singapore: Springer. https://doi.org/10.1007/978-981-15-9635-3_9

Nagarajan, K.J.; Balaji, A.N.; Basha, K.S.; Ramanujam, N.R.; Kumar, R.A. 2020. Effect of agrowaste $\alpha$-cellulosic micro filler on the mechanical and thermal behavior of epoxy composites. Int J Biol Macromol 152: 327-339. https://doi.org/10.1016/j.ijbiomac.2020.02.255

Naghmouchi, I.; Espinach, F.X.; Mutjé, P.; Boufi, S. 2015. Polypropylene composites based on lignocellulosic fillers: how the filler morphology affects the composite properties. Mater Des 65(1980-2015): 454461. http://dx.doi.org/10.1016/j.matdes.2014.09.047

Patil, A.Y.; Banapurmath, N.R.; Yaradoddi, J.S.; Kotturshettar, B.B.; Shettar, A.S.; Basavaraj, G.D.; Keshavamurthy, R.; Khan, T.Y.; Mathad, S.N. 2019. Experimental and simulation studies on waste vegetable peels as bio-composite fillers for light-duty applications. Arab J Sci Eng 44(9): 7895-7907. https:// doi.org/10.1007/s13369-019-03951-2

Rajinipriya, M.; Nagalakshmaiah, M.; Robert, M.; Elkoun, S. 2018. Importance of agricultural and industrial waste in the field of nanocellulose and recent industrial developments of wood-based nanocellulose: a review. ACS Sustain Chem Eng 6(3): 2807-2828. https://doi.org/10.1021/acssuschemeng.7b03437

Saba, N.; Tahir, P.M.; Jawaid, M. 2014. A review on the potentiality of nano filler/natural fiber-filled polymer hybrid composites. Polymers 6(8): 2247-2273. https://doi.org/10.3390/polym6082247

Salasinska, K.; Barczewski, M.; Górny, R.; Kloziński, A. 2018. Evaluation of highly filled epoxy composites modified with walnut shell waste filler. Polym Bull 75(6): 2511-2528. https://doi.org/10.1007/s00289$017-2163-3$

Santulli, C.; Rallini, M.; Puglia, D.; Gabrielli, S.; Torre, L.; Marcantoni, E. 2020. Characterization of Licorice Root Waste for Prospective Use as Filler in more Eco-Friendly Composite Materials. Processes 8(6): 733. https://doi.org/10.3390/pr8060733

Shahzad, Asim. 2015. Mechanical properties of eco-friendly polymer nanocomposites. Eco-Friendly Polymer Nanocomposites. 527-559.Springer: New Delhi. https://doi.org/10.1007/978-81-322-2470-9_18

Wen, J.L.; Wang, H.M.; Ma, C.Y.; Yuan, T.Q.; Sun, R.C. 2021. Value-added products from lignin: IsolationValue-added products from lignin: Isolation, characterization, and applications. Biomass, Biofuels, Biochemicals (Elsevier) 33-55. https://doi.org/10.1016/B978-0-12-820294-4.00009-0

Yildirim, A.; Acay, H. 2021. Applications of Biodegradable Green Composites. In Green Composites. Materials Horizons: From Nature to Nanomaterials., edited by Balakrishnan, P.; Thomas, S. 373-392. Singapore: Springer. https://doi.org/10.1007/978-981-15-9643-8_14

Zaaba, N.F.; Ismail, H. 2019. A review on peanut shell powder reinforced polymer composites PolymPlast. Technol Mater 58(4): 349-365. https://doi.org/10.1080/03602559.2018.1471720

Zhang, J.; Terrones, M.; Park, C.R.; Mukherjee, R.; Monthioux, M.; Koratkar, N.; Kim, Y.S.; Hurt, R.; Frackowiak, E.; Enoki, T.; Chen, Y. 2016. Carbon science in 2016: Status, challenges, and perspectives. Carbon 98(70): 708-732. http://dx.doi.org/10.1016/j.carbon.2015.11.060 